\title{
Plasma adrenomedullin as an indicator of prognosis after acute myocardial infarction
}

N Nagaya, T Nishikimi, M Uematsu, Y Yoshitomi, Y Miyao, S Miyazaki, Y Goto, S Kojima, M Kuramochi, H Matsuo, K Kangawa, H Nonogi
Department of Clinical Research, Tohsei

National Hospital,

Shizuoka, Japan

Y Yoshitomi

S Kojima

M Kuramochi

Correspondence to:

Dr Nishikimi.

Accepted for publication 4 December 1998

Keywords: prognosis; adrenomedullin; myocardial infarction; heart failure

Adrenomedullin is a potent hypotensive peptide that has recently been isolated from human phaeochromocytoma. ${ }^{1}$ The peptide consists of 52 amino acids with an intramolecular disulphide bond, sharing slight homology with calcitonin gene related peptide and amylin.

\begin{abstract}
Department of Internal Medicine, National

Cardiovascular

Centre, 5-7-1

Fujishirodai, Suita,

Osaka 565, Japan

N Nagaya

T Nishikimi

Y Miyao

S Miyazaki

Y Goto

H Nonogi

Research Institute, National

Cardiovascular Centre

M Uematsu

H Matsuo

K Kangawa

Abstract

Objective-To elucidate whether prognosis after acute myocardial infarction can be predicted by measuring plasma adrenomedullin, a novel vasorelaxant peptide.

Patients and design-Plasma adrenomedullin concentrations on day 2 after myocardial infarction were measured in 113 patients with myocardial infarction with other clinical and haemodynamic variables related to mortality.

Results-During a mean follow up period of 25 months, 16 patients died of cardiac causes. Plasma adrenomedullin concentrations on day 2 increased significantly in patients with myocardial infarction compared with controls (mean (SD), $12.3(8.8)$ $v 4.9$ (1.0) pmol/1, p $<0.001)$. Plasma adrenomedullin correlated negatively with left ventricular ejection fraction on admission $(r=-0.47, \mathrm{p}<0.001)$, although it did not significantly correlate with any other haemodynamic variable. By univariate Cox proportional hazards analysis, plasma adrenomedullin, age, coronary reperfusion, maximum creatine kinase concentrations, pulmonary congestion, pulmonary capillary wedge pressure, cardiac index, and left ventricular ejection fraction were all significantly related to mortality. Among the noninvasive variables, only plasma adrenomedullin was an independent predictor of mortality after myocardial infarction $(p<0.05)$. The Kaplan-Meier survival curves based on the median plasma adrenomedullin concentration (10.3 pmol/1) showed that patients with high plasma adrenomedullin had a higher mortality than those with low plasma adrenomedullin ( $p<0.01)$.

Conclusions-Plasma adrenomedullin on day 2 after myocardial infarction is strongly associated with long term mortality, and thus may complement standard prognostic indicators.

(Heart 1999;81:483-487)
\end{abstract}

Immunoreactive adrenomedullin has been detected in human plasma, and human adrenomedullin messenger RNA has been reported to be highly expressed not only in the phaeochromocytoma, but also in the adrenal medulla, kidney, lung, peripheral vascular bed, and the cardiac ventricles. ${ }^{2}$ Several studies have shown that the plasma adrenomedullin concentrations are increased in patients with hypertension or renal failure. ${ }^{3}$ With its potent vasodilator, ${ }^{14}$ natriuretic, and diuretic effects, ${ }^{56}$ adrenomedullin may be involved in the regulation of body fluid and thus in cardiovascular homeostasis.

Recently, we and others have shown that plasma adrenomedullin concentrations are increased in patients with heart failure in proportion to clinical severity, ${ }^{78}$ and that plasma adrenomedullin is increased at an early stage of acute myocardial infarction. ${ }^{9}{ }^{10}$ Both the failing ventricle and the disordered peripheral vascular bed have been shown to be responsible for the high plasma adrenomedullin in patients with heart failure. ${ }^{11}{ }^{12}$ These findings raise the possibility that high plasma adrenomedullin concentrations in an early phase of myocardial infarction are related to left ventricular dysfunction, and thus may be associated with long term mortality in patients with myocardial infarction. Indeed, Richards et al have shown that plasma adrenomedullin on days 2 to 4 after myocardial infarction is related to mortality, but they found it a less sensitive indicator than $\mathrm{N}$-terminal pro-brain natriuretic peptide. ${ }^{13}$ However, plasma adrenomedullin concentrations are reported to reach a peak on days 1 to 2 after myocardial infarction, earlier than measured by Richards, and to decrease rapidly thereafter. ${ }^{9}{ }^{10}$ Thus it is still unclear whether plasma adrenomedullin measured in the acute phase after myocardial infarction is a good indicator of mortality.

In the present study, we investigated whether prognosis after myocardial infarction can be predicted by measuring plasma adrenomedullin concentrations on day 2 after the infarct.

\section{Methods}

STUDY PATIENTS

The study subjects were 113 consecutive patients who underwent coronary angiography within 24 hours of the onset of myocardial infarction from October 1994 to August 1996 (86 men and 27 women, mean age 62 years, range 30 to 85 ). The diagnosis of myocardial infarction was based on the following criteria: chest pain $\geqslant 30$ minutes in duration; ST segment elevation $\geqslant 0.1 \mathrm{mV}$ in two or more ECG leads 
Table 1 Comparison of patient characteristics in relation to values of plasma adrenomedullin above and below the median value (10.3 pmol/l)

\begin{tabular}{|c|c|c|c|}
\hline & $\begin{array}{l}\text { Low AM group } \\
(n=57)\end{array}$ & $\begin{array}{l}\text { High AM group } \\
(n=56)\end{array}$ & p Value \\
\hline \multicolumn{4}{|l|}{ Demographics } \\
\hline Cardiovascular deaths (n) & 3 & 13 & $<0.01$ \\
\hline Age (years) & $60(11)$ & $64(12)$ & NS \\
\hline Male sex (n) & 43 & 43 & NS \\
\hline \multicolumn{4}{|l|}{ Clinical variables } \\
\hline Anterior MI (n) & 22 & 39 & $<0.01$ \\
\hline Previous MI (n) & 5 & 8 & NS \\
\hline Successful reperfusion (n) & 51 & 46 & NS \\
\hline Killip II, III, IV (n) & 12 & 22 & $<0.05$ \\
\hline Previous angina (n) & 34 & 37 & NS \\
\hline Maximum CK (U/1) & $3526(3539)$ & 4368 (3398) & NS \\
\hline Hypertension (n) & 29 & 32 & NS \\
\hline Haemodynamic data on admission $(n=108)$ & $(\mathrm{n}=55)$ & $(\mathrm{n}=53)$ & \\
\hline Heart rate (beats/min) & $79(17)$ & $82(18)$ & NS \\
\hline $\mathrm{SBP}(\mathrm{mm} \mathrm{Hg})$ & $127(20)$ & $128(25)$ & NS \\
\hline PCWP (mm Hg) & $13(6)$ & $15(7)$ & NS \\
\hline $\mathrm{RAP}(\mathrm{mm} \mathrm{Hg})$ & $7(4)$ & $7(5)$ & NS \\
\hline mPAP $(\mathrm{mm} \mathrm{Hg})$ & $20(6)$ & $21(8)$ & NS \\
\hline Cardiac index $\left(1 / \mathrm{min} / \mathrm{m}^{2}\right)$ & $3.0(0.9)$ & $2.6(0.7)$ & $<0.05$ \\
\hline LVEF on admission (\%) & $49(10)$ & $39(10)$ & $<0.001$ \\
\hline \multicolumn{4}{|l|}{ Drugs on discharge } \\
\hline ACE inhibitor (n) & 13 & 22 & NS \\
\hline Diuretics (n) & 4 & 14 & $<0.01$ \\
\hline Calcium antagonist (n) & 40 & 39 & NS \\
\hline Nitrate (n) & 39 & 36 & NS \\
\hline$\beta$ Blocker (n) & 4 & 4 & NS \\
\hline Plasma AM on day $2(\mathrm{pmol} / \mathrm{l})$ & $7.3(2.2)$ & $17.4(10.1)$ & $<0.001$ \\
\hline
\end{tabular}

Values are means (SD) unless otherwise stated.

ACE, angiotensin converting enzyme; AM, adrenomedullin; CK, creatine kinase; Killip, Killip heart failure classification; LVEF, left ventricular ejection fraction; MI, myocardial infarction; mPAP, mean pulmonary arterial pressure; PCWP, pulmonary capillary wedge pressure; RAP, mean right atrial pressure; SBP, systolic blood pressure.

in the same vascular territory; and subsequent rise in creatine kinase by more than twofold the upper limit of the normal range. We excluded patients with renal failure on admission (serum creatinine $\geqslant 133 \mu \mathrm{mol} / 1)$.

Anterior myocardial infarction occurred in 61 patients, inferior myocardial infarction in 36 , and posterolateral myocardial infarction in 16. This was confirmed by ECG, echocardiography, and coronary angiography. Coronary reperfusion was achieved in 97 patients ( 55 by coronary angioplasty, 19 by intracoronary thrombolysis, and 23 with spontaneous reperfusion). Thirty healthy subjects (16 men and 14 women, mean age 58 years, range 50 to 69) served as a control group. All subjects provided informed consent.

BLOOD SAMPLING AND ASSAY FOR PLASMA ADRENOMEDULLIN

Blood samples were taken from the antecubital vein in the supine position on day 2 in all patients. The blood was immediately transferred into chilled glass tube containing disodium EDTA $(1 \mathrm{mg} / \mathrm{ml})$ and aprotinin (500 $\mathrm{U} / \mathrm{ml}$ ) and centrifuged immediately at $4^{\circ} \mathrm{C}$. The plasma samples were frozen and stored at $-80^{\circ} \mathrm{C}$, and were then extracted before radioimmunoassay. Briefly, Sep-Pak C18 cartridges (Millipore-Waters, Milford, Massachusetts, USA) were preconditioned with $5 \mathrm{ml}$ each of chloroform, methanol, $50 \%$ acetonitrile containing $0.1 \%$ trifluoroacetic acid (TFA), $0.1 \%$ TFA, and saline. Plasma $(2 \mathrm{ml})$ was acidified with $24 \mu \mathrm{l}$ of $1 \mathrm{~N} \mathrm{HCl}$, diluted with $2 \mathrm{ml}$ saline, and then loaded onto a Sep-Pak C18 cartridge. After the column was washed with $5 \mathrm{ml}$ each of saline, $0.1 \%$ TFA, and $20 \%$ acetonitrile containing $0.1 \%$ TFA, the absorbed materials were eluted with $4 \mathrm{ml}$ of $50 \%$ acetonitrile containing $0.1 \%$ TFA. The eluate was then freeze dried. The freeze dried material was dissolved in radioimmunoassay buffer and the clear solution was radioimmunoassayed. The radioimmunoassay for adrenomedullin has been reported previously. ${ }^{14}$

\section{MEASUREMENTS OF HAEMODYNAMICS AND} CARDIAC FUNCTION

Immediately after admission and on day 2 after myocardial infarction, pulmonary capillary wedge pressure, mean right atrial pressure, mean pulmonary arterial pressure, and cardiac index were measured using a thermodilution catheter in 108 patients. Left ventricular ejection fraction on admission was calculated by left ventriculography $(n=101)$ or echocardiography $(n=12) \cdot{ }^{15}{ }^{16}$ Clinical characteristics, haemodynamic variables, and cardiac function of the patients, grouped into "low" and "high" plasma adrenomedullin around the mean concentration of $10.3 \mathrm{pmol} / \mathrm{l}$, are summarised in table 1 .

\section{SURVIVAL ANALYSIS}

Survival was estimated from the onset of myocardial infarction to 20 January 1998, or the death of the patient. Patients who died of noncardiac causes were judged at the same time points.

\section{STATISTICAL ANALYSIS}

Numerical values were expressed as mean (SD). Study patients were divided into two groups according to the median adrenomedullin value. Comparisons of variables between the two groups were made by Fisher's exact test or the unpaired Student's $t$ test. Comparisons of plasma adrenomedullin concentrations among the groups were made using the one way analysis of variance followed by the Scheffe's multiple comparison test. The prognostic value of each variable was tested by a univariate Cox proportional hazards regression analysis. By a multivariate model, the prognostic power of plasma adrenomedullin was compared with that of each non-invasive variable. Survival curves were derived using the Kaplan-Meier method and were compared using log-rank tests. Receiver operating characteristics were generated from multiple sensitivity/specificity pairs. A p value of $<0.05$ was considered statistically significant.

\section{Results}

The mean follow up period was 25 (10) months (range two days to 39 months). Sixteen patients $(14 \%)$ died of cardiovascular causes during the follow up period-progressive heart failure in nine, sudden cardiac death in five, and recurrence of myocardial infarction in two. Two patients died of non-cardiovascular causes (lung cancer and renal failure). No patient defaulted from the follow up. 

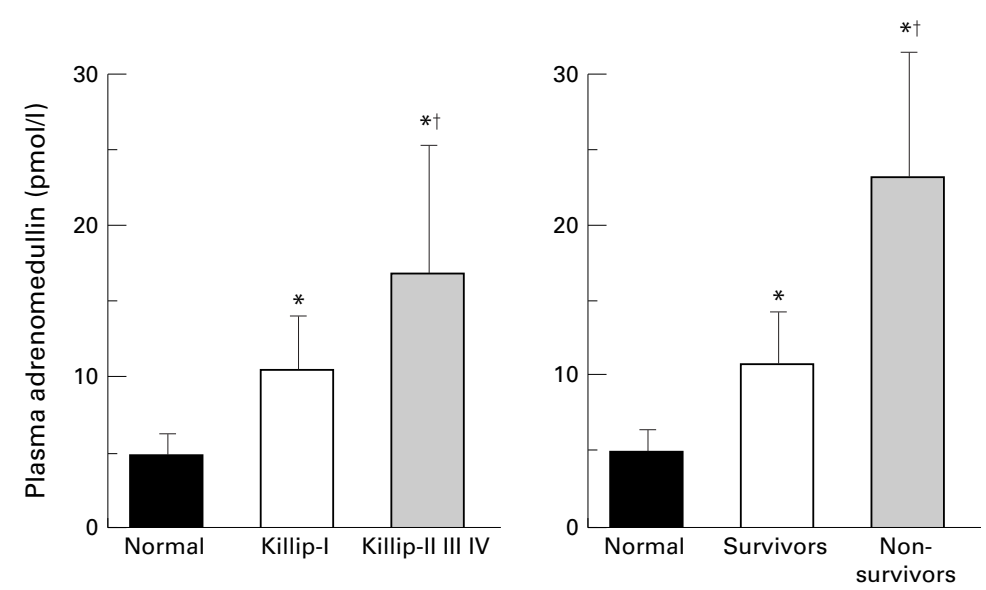

Figure 1 Left panel: Relation between plasma adrenomedullin on day 2 after infarction and Killip's classification. Right panel: Relation between plasma adrenomedullin on day 2 and mortality after acute myocardial infarction. ${ }^{*} p<0.05 v$ normal control value; $\dagger p<0.05 v$ values in Killip class I or survivors. Values are means, error bars $=S D$.

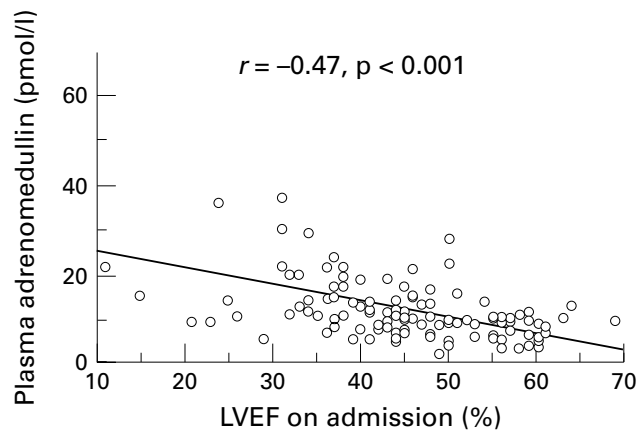

Figure 2 Relation between plasma adrenomedullin on day 2 and left ventricular ejection fraction (LVEF) on admission in patients with acute myocardial infarction.

PLASMA ADRENOMEDULLIN AND CLINICAL, HAEMODYNAMIC, AND CARDIAC FUNCTION VARIABLES

Plasma adrenomedullin on day 2 was significantly increased in patients with myocardial infarction compared with control subjects (12.3 (8.8) $v 4.9$ (1.0) pmol/1, p < 0.001). Plasma adrenomedullin on day 2 was significantly higher in patients with heart failure (Killip class II or more) than in those without (fig 1). Plasma adrenomedullin in nonsurvivors was markedly increased compared with survivors (fig 1). Plasma adrenomedullin

Table 2 Univariate predictors of mortality in patients with acute myocardial infarction

\begin{tabular}{llll}
\hline Variable & $\begin{array}{l}\text { Risk ratio } \\
\text { estimate }\end{array}$ & $95 \%$ CI & p Value \\
\hline Plasma AM on day 2 & 1.072 & 1.045 to 1.099 & $<0.0001$ \\
Age & 1.073 & 1.021 to 1.127 & 0.0051 \\
Male sex & 0.524 & 0.190 to 1.444 & 0.2114 \\
Anterior MI & 2.447 & 0.844 to 7.090 & 0.0992 \\
Previous MI & 1.175 & 0.265 to 5.210 & 0.8314 \\
Reperfusion & 0.323 & 0.112 to 0.934 & 0.0369 \\
Previous angina & 0.993 & 0.360 to 2.739 & 0.9894 \\
Maximum CK & 1.004 & 0.998 to 1.010 & 0.1895 \\
Pulmonary congestion & 6.543 & 2.260 to 18.946 & 0.0005 \\
Hypertension & 2.778 & 0.894 to 8.632 & 0.0773 \\
Haemodynamics on admission & & & \\
$\quad$ Heart rate & 1.025 & 0.998 to 1.053 & 0.0677 \\
$\quad$ SBP & 0.998 & 0.973 to 1.023 & 0.8690 \\
$\quad$ PCWP & 1.137 & 1.045 to 1.237 & 0.0029 \\
$\quad$ Cardiac index & 0.221 & 0.085 to 0.522 & 0.0008 \\
LVEF on admission & 0.907 & 0.868 to 0.947 & $<0.0001$ \\
\hline
\end{tabular}

$\mathrm{AM}$, adrenomedullin; CI, confidence interval; CK, creatine kinase; LVEF, left ventricular ejection fraction; MI, myocardial infarction; PCWP, pulmonary capillary wedge pressure; SBP, systolic blood pressure.
Table 3 Multivariate predictors of mortality in patients with acute myocardial infarction

\begin{tabular}{|c|c|c|c|}
\hline Variable & $\begin{array}{l}\text { Risk ratio } \\
\text { estimate }\end{array}$ & $95 \% C I$ & $p$ Value \\
\hline Plasma AM on day 2 & 1.043 & 1.008 to 1.079 & 0.0144 \\
\hline Age & 1.047 & 0.989 to 1.108 & 0.1135 \\
\hline Male sex & 0.509 & 0.153 to 1.690 & 0.2701 \\
\hline Anterior MI & 1.181 & 0.279 to 5.001 & 0.8213 \\
\hline Previous MI & 1.080 & 0.185 to 6.318 & 0.9318 \\
\hline Previous angina & 1.169 & 0.342 to 3.997 & 0.8037 \\
\hline Hypertension & 1.958 & 0.495 to 7.749 & 0.3385 \\
\hline Maximum CK & 1.009 & 0.999 to 1.018 & 0.0761 \\
\hline $\begin{array}{l}\text { Pulmonary } \\
\text { congestion }\end{array}$ & 3.736 & 0.938 to 14.881 & 0.0616 \\
\hline Heart rate on & & & \\
\hline admission & 1.013 & 0.979 to 1.048 & 0.4580 \\
\hline SBP on admission & 1.006 & 0.981 to 1.032 & 0.6410 \\
\hline
\end{tabular}

$\mathrm{AM}$, adrenomedullin; CI, confidence interval; CK, creatine kinase; MI, myocardial infarction; SBP, systolic blood pressure.

correlated negatively with left ventricular ejection fraction on admission $(r=-0.47$, $\mathrm{p}<0.001$, fig 2), although the values did not correlate significantly with any of the other haemodynamic variables, such as pulmonary capillary wedge pressure or cardiac index, either on admission or on day 2 after myocardial infarction.

UNIVARIATE AND MULTIVARIATE PREDICTORS OF MORTALITY

By univariate analysis, plasma adrenomedullin on day 2 , age, coronary reperfusion, maximum creatine kinase, pulmonary congestion, pulmonary capillary wedge pressure, cardiac index, and left ventricular ejection fraction were all significantly related with mortality (table 2 ). By multivariate analysis, among the non-invasive variables only plasma adrenomedullin was an independent predictor of mortality after myocardial infarction (table 3).

KAPLAN-MEIER LIFETIME ANALYSIS

Kaplan-Meier survival curves related to the median plasma adrenomedullin value (10.3 $\mathrm{pmol} / \mathrm{l})$ showed that patients with high plasma adrenomedullin had a significantly lower survival rate than those with low plasma adrenomedullin (log-rank test, $\mathrm{p}<0.01$, fig 3 ).

RECEIVER OPERATING CHARACTERISTICS

We examined the sensitivity and specificity of plasma adrenomedullin on day 2 , and left ventricular ejection fraction on admission, for

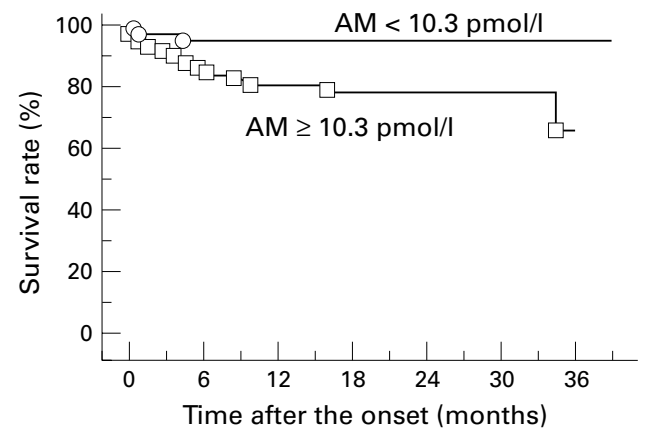

Figure 3 Kaplan-Meier survival curves according to the median value of plasma adrenomedullin (AM) on day 2 after acute myocardial infarction. Patients with high ( $\geqslant 10.3$ pmol/l) plasma AM concentrations had a significantly lower survival rate than those with low plasma $A M(<10.3$ pmolll) (log-rank test, $p<0.01)$. 


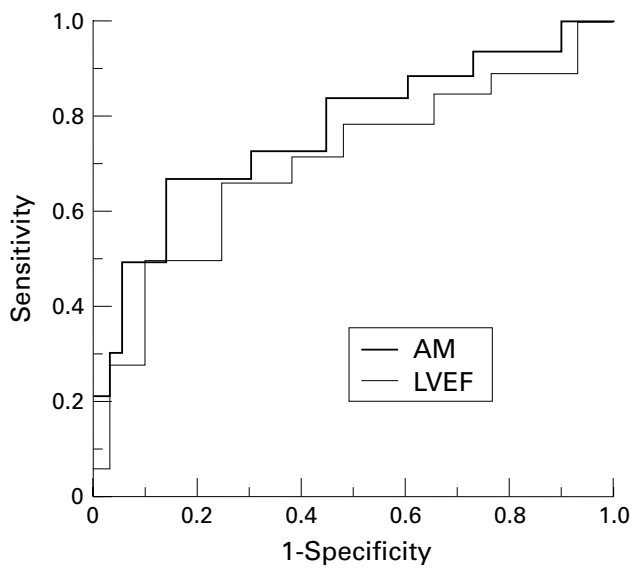

Figure 4 Receiver operating characteristics for plasma adrenomedullin (AM) and left ventricular ejection fraction (LVEF) for predicting mortality. The true positive rates (sensitivity) and false positive rates (1-specificity) are plotted for various cut off values of plasma AM and LVEF predicting mortality.

Table 4 Plasma adrenomedullin (AM) and left ventricular ejection fraction (LVEF) in patients with $L V E F$ below $40 \%$

\begin{tabular}{|c|c|c|c|}
\hline & $\begin{array}{l}\text { Survivors } \\
(n=22)\end{array}$ & $\begin{array}{l}\text { Non-survivors } \\
(n=12)\end{array}$ & $p$ Value \\
\hline Plasma AM (pmol/1) & $13.9(5.3)$ & $25.9(18.6)$ & $<0.01$ \\
\hline $\operatorname{LVEF}(\%)$ & $33(6)$ & $30(7)$ & NS \\
\hline
\end{tabular}

Values are means (SD).

predicting mortality. Receiver operating characteristics showed that the prognostic value of plasma adrenomedullin on day 2 was comparable to that of left ventricular ejection fraction on admission (fig 4). Furthermore, in a subsample of 34 patients with a left ventricular ejection fraction below $40 \%$, which has been shown to be strongly associated with a poor prognosis, ${ }^{17}$ plasma adrenomedullin concentrations on day 2 were significantly higher in non-survivors $(\mathrm{n}=12)$ than in survivors $(n=22)$, whereas left ventricular ejection fraction did not differ significantly between the two groups (table 4).

\section{Discussion}

We showed that plasma adrenomedullin concentrations on day 2 were markedly increased in patients with heart failure (Killip class II or more) after myocardial infarction and were negatively correlated with left ventricular ejection fraction; that among the non-invasive variables, only plasma adrenomedullin was an independent predictor of mortality by multivariate analysis; and that, using Kaplan-Meier survival curves, patients with plasma adrenomedullin values above the median had a significantly greater mortality than those with values below the median.

Earlier studies have shown that adrenomedullin is produced mainly by endothelial cells and by vascular smooth muscle cells regulating vascular tone. ${ }^{14}{ }^{18-20}$ More recently, the failing ventricle has also been shown to secrete adrenomedullin into plasma. ${ }^{11}{ }^{12}$ Adrenomedullin synthesis is promoted in vitro by a variety of cytokines, such as interleukin- $1 \beta$ and tumour necrosis factor $\alpha,{ }^{18}$ both of which increase in parallel with myocardial tissue damage after myocardial infarction. ${ }^{21}{ }^{22}$ These findings raise the possibility that both the failing ventricle and the disordered peripheral vascular bed contribute to the increased plasma adrenomedullin in patients with myocardial infarction, and that high plasma adrenomedullin concentrations are related to severe left ventricular dysfunction. In our present study, a high plasma adrenomedullin was strongly associated with congestive heart failure complicating myocardial infarction. In addition, plasma adrenomedullin concentrations after myocardial infarction showed a significant negative correlation with left ventricular ejection fraction. These results are consistent with previous reports. ${ }^{79}$

Richards et al have shown very recently that plasma adrenomedullin on days 2 to 4 after myocardial infarction is related to mortality, but they found the prognostic value of adrenomedullin to be inferior to that of $\mathrm{N}$-terminal pro-brain natriuretic peptide. ${ }^{13}$ It remains unclear, however, whether plasma adrenomedullin measured at an earlier point after myocardial infarction is related to mortality. In the present study, we examined the prognostic value of plasma adrenomedullin on day 2 , because plasma adrenomedullin concentrations have been shown to reach their peak on days 1 to 2 after myocardial infarction. ${ }^{9} 10$ Using a multivariate Cox proportional hazards regression analysis, we showed that the plasma adrenomedullin concentration on day 2 was indeed an independent predictor of the mortality among other non-invasive variables.

In a large scale randomised study it was found that left ventricular ejection fraction was an independent predictor of mortality. ${ }^{17}$ In our study we also showed, in a univariate analysis, that left ventricular ejection fraction was related to mortality. We then examined the sensitivity and specificity of various cut off values of plasma adrenomedullin and compared them with left ventricular ejection fraction for predicting mortality. A receiver operating characteristic curve showed that the prognostic value of plasma adrenomedullin on day 2 was comparable to that of left ventricular ejection fraction on admission. In a subsample of patients with severe left ventricular dysfunction associated with the likelihood of a poor outcome, plasma adrenomedullin on day 2 was markedly higher in non-survivors than in survivors, whereas left ventricular ejection fraction did not differ significantly between the two groups. These results suggest that plasma adrenomedullin concentrations on day 2 after myocardial infarction may complement left ventricular ejection fraction as a prognostic indicator, particularly in patients with a low ejection fraction.

\section{STUDY LIMITATIONS}

First, patients with renal failure were excluded from this study because a marked rise in plasma adrenomedullin occurs under these circumstances. ${ }^{3}$ Thus we do not know whether plasma adrenomedullin can also predict survival in such patients. Second, sampling at different 
times after myocardial infarction may alter the prognostic value of the test, and we did not assess this in the present study. Nevertheless, earlier studies suggested that sampling on day 2 was most likely to catch the peak value of adrenomedullin after myocardial infarction. ${ }^{9}{ }^{10}$

CONCLUSIONS

Plasma adrenomedullin concentrations on day 2 after myocardial infarction are strongly associated with long term mortality, and thus may complement standard prognostic indicators.

We thank Yoko Saito BS for technical assistance and Nobuo Shirahashi BS for helpful advice regarding statistical analysis. This work was supported in part by Special Coordination Funds for Promoting Science and Technology (Encouragement System of COE) from the Science and Technology Agency of Japan.

1 Kitamura K, Kangawa K, Kawamoto M, et al. Adrenomedullin: a novel hypotensive peptide isolated from human pheochromocytoma. Biochem Biophys Res Commun pheochromocytoma.

2 Ichiki Y, Kitamura K, Kangawa K, et al. Distribution and characterization of immunoreactive adrenomedullin in characterization of immunoreactive adrenomedullin

3 Ishimitsu T, Nishikimi T, Saito Y, et al. Plasma levels of adrenomedullin, a hypotensive peptide, in patients with hypertension and renal failure. F Clin Invest 1994;94:215861.

4 Nakamura M, Yoshida H, Makita S, et al. Potent and longlasting vasodilatory effects of adrenomedullin in humans: comparisons between normal subjects and patients with chronic heart failure. Circulation 1997;95:1214-21.

5 Miura K, Ebara T, Okumura M, et al. Attenuation of adrenomedullin-induced renal vasodilation by N-nitro-Larginine but not glibenclamide. Brf Pharmacol 1995;115: 917-24.

6 Majid DSA, Kadowitz PJ, Coy DH, et al. Renal responses to intra-arterial administration of adrenomedullin in dogs.

7 Nishikimi T, Saito Y, Kitamura K, et al. Increased plasma levels of adrenomedullin in patients with heart failure. $\mathscr{f} \mathrm{Am}$ levels of adrenomedullin in patien

8 Jougasaki M, Wei C-M, McKinley LJ, et al. Elevation of circulating and ventricular adrenomedullin in human congestive heart failure. Circulation 1995;92:286-9.
9 Miyao Y, Nishikimi T, Miyazaki S, et al. Increased plasma levels of adrenomedullin in patients with acute myocardial infarction in proportion to the clinical severity. Heart 1998; 79:39-44

10 Kobayashi K, Kitamura K, Hirayama N, et al. Increased plasma adrenomedullin in acute myocardial infarction. $\mathrm{Am}$ Heart f 1996;131:676-80.

11 Jougasaki M, Rodeheffer RJ, Redfield MM, et al. Cardiac secretion of adrenomedullin in human heart failure. $\mathcal{f}$ Clin Invest 1996;97:2370-6.

12 Nishikimi T, Horio T, Sasaki T, et al. Cardiac production and secretion of adrenomedullin are increased in heart failure. Hypertension 1997;30:1369-75.

13 Richards AM, Nicholls MG, Yandle TG, et al. Plasma $\mathrm{N}$-terminal pro-brain natriuretic peptide and adrenomedullin: new neurohormonal predictors of left ventricular function and prognosis after myocardial infarcventricular function and prognosis
tion. Circulation 1998;97:1921-9.

14 Kitamura K, Ichiki Y, Tanaka $M$, et al. Immunoreactive adrenomedullin in human plasma. FEBS Lett 1994;341: $288-90$

15 Sandler $\mathrm{H}$, Dodge $\mathrm{H}$. Use of single plane angiocardiograms for the calculation of left ventricular volume in man. $\mathrm{Am}$ Heart 7 1968;75:325-34.

16 Schiller NB, Shah PM, Crawford M, et al. Recommendations for quantitation of the left ventricle by twodimensional echocardiography: American Society of Echocardiography Committee on Standards, Subcommittee on Quantitation of Two-dimensional Echocardiograms. $\mathcal{F} \mathrm{Am}$ Soc Echocardiogr 1989;2:358-67.

17 Sanz G, Castaner A, Betriu A, et al. Determinants of prognosis in survivors of myocardial infarction: a prospective clinical angiographic study. N Engl f Med 1982;306:106570 .

18 Sugo S, Minamino N, Kangawa K, et al. Endothelial cells actively synthesize and secrete adrenomedullin. Biochem Biophys Res Commun 1994;201:1160-6.

19 Sugo S, Minamino N, Shoji H, et al. Interleukin-1, tumor necrosis factor and lipopolysaccharide additively stimulate production of adrenomedullin in vascular smooth muscle cells. Biochem Biophys Res Commun 1995;207:25-32.

20 Nossaman BD, Feng CJ, Kaye AD, et al. Pulmonary vasodilator responses to adrenomedullin are reduced by NOS inhibitors in rats but not in cats. Am f Physiol 1996;270: L782-9.

21 Hirschl MM, Gwechenberger M, Binder T, et al. Assessment of myocardial injury by serum tumour necrosis factor alpha measurements in acute myocardial infarction. Eur Heart f 1996;17:1852-9.

22 Guillen I, Blanes M, Gomez-Lechon M, et al. Cytokine signaling during myocardial infarction: sequential appearance of IL-1 $\beta$ and IL-6. Am $\mathcal{F}$ Physiol 1995;269:R229-35. 